

\section{EXPLAINING EXTREME EVENTS OF 20I4 FROM A CLIMATE PERSPECTIVE}

\section{Editors}

Stephanie C. Herring, Martin P. Hoerling, James P. Kossin, Thomas C. Peterson, and Peter A. Stott

Special Supplement to the

Bulletin of the American Meteorological Society

Vol. 96, No. I2, December 2015 
CORRESPONDING EDITOR:

Stephanie C. Herring, PhD

NOAA National Centers for Environmental Information

325 Broadway, E/CC23, Rm IB-I3I

Boulder, CO 80305-3328

E-mail: stephanie.herring@noaa.gov

COVER CREDITS:

Front: (CiStockphotos.com/coleong-Winter snow, Boston, Massachusetts, United States.

BACK: (iStockphotos.com/nathanphoto-Legget, California, United States - August 13, 20I4: CAL FIRE helicopter surveys a part of the Lodge Fire, Mendocino County.

\section{HOW TO CITE THIS DOCUMENT}

Citing the complete report:

Herring, S. C., M. P. Hoerling, J. P. Kossin, T. C. Peterson, and P. A. Stott, Eds., 20I5: Explaining Extreme Events of 2014 from a Climate Perspective. Bull. Amer. Meteor. Soc., 96 (I2), SI-SI72.

Citing a section (example):

Yoon, J. H., S.-Y. S. Wang, R. R. Gillies, L. Hipps, B. Kravitz, and P. J. Rasch, 20I5: Extreme fire season in California: A glimpse into the future? [in "Explaining Extremes of 20I4 from a Climate Perspective”]. Bull. Amer. Meteor. Soc., 96 (I2), S5-S9.

\section{EDITORIAL AND PRODUCTION TEAM}

Riddle, Deborah B., Lead Graphics Production, NOAA/NESDIS National Centers for Environmental Information,

Asheville, NC

Love-Brotak, S. Elizabeth, Graphics Support, NOAA/NESDIS National Centers for Environmental Information,

Asheville, NC

Veasey, Sara W., Visual Communications Team Lead, NOAA/ NESDIS National Centers for Environmental Information, Asheville, NC

Griffin, Jessicca, Graphics Support, Cooperative Institute for Climate and Satellites-NC, North Carolina State University, Asheville, NC

Maycock, Tom, Editorial Support, Cooperative Institute for Climate and Satellites-NC, North Carolina State University, Asheville, NC
Misch, Deborah J., Graphics Support, LMI Consulting, Inc., NOAA/NESDIS National Centers for Environmental Information, Asheville, NC

Osborne, Susan, Editorial Support, LMI Consulting, Inc., NOAA/NESDIS National Centers for Environmental Information, Asheville, NC

Schreck, Carl, Editorial Support, Cooperative Institute for Climate and Satellites-NC, North Carolina State University, and NOAA/NESDIS National Centers for Environmental Information, Asheville, NC

Sprain, Mara, Editorial Support, LAC Group, NOAA/NESDIS National Centers for Environmental Information, Asheville, NC

Young, Teresa, Graphics Support, STG, Inc., NOAA/NESDIS National Centers for Environmental Information, Asheville, NC 
Abstract.

I. Introduction to Explaining Extreme Events of 2014 from a Climate Perspective .................................

2. Extreme Fire Season in California: A Glimpse Into the Future? …………………..................................

3. How Unusual was the Cold Winter of 2013/14 in the Upper Midwest?............................................10

4. Was the Cold Eastern Us Winter of 2014 Due to Increased Variability? .............................................15

5. The 2014 Extreme Flood on the Southeastern Canadian Prairies .................................................... 20

6. Extreme North America Winter Storm Season of 2013/14: Roles of Radiative Forcing and the Global Warming Hiatus.......................................................................................................................... 25

7. Was the Extreme Storm Season in Winter 2013/14 Over the North Atlantic and the United Kingdom Triggered by Changes in the West Pacific Warm Pool?.

8. Factors Other Than Climate Change, Main Drivers of 2014/15 Water Shortage in Southeast Brazil..

9. Causal Influence of Anthropogenic Forcings on the Argentinian Heat Wave of December 2013

10. Extreme Rainfall in the United Kingdom During Winter 2013/14: The Role of Atmospheric Circulation and Climate Change.

II. Hurricane Gonzalo and its Extratropical Transition to a Strong European Storm.............................5I

12. Extreme Fall 2014 Precipitation in the Cévennes Mountains ........................................................ 56

13. Record Annual Mean Warmth Over Europe, the Northeast Pacific, and the Northwest Atlantic During 2014: Assessment of Anthropogenic Influence.

14. The Contribution of Human-Induced Climate Change to the Drought of 2014 in the Southern

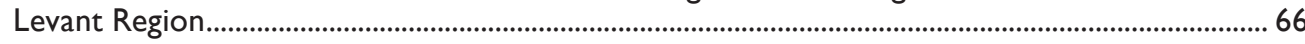

15. Drought in the Middle East and Central-Southwest Asia During Winter 2013/14............................ I

16. Assessing the Contributions of East African and West Pacific Warming to the 2014 Boreal Spring East African Drought

17. The 2014 Drought in the Horn of Africa: Attribution of Meteorological Drivers.

18. The Deadly Himalayan Snowstorm of October 2014: Synoptic Conditions and Associated Trends

19. Anthropogenic Influence on the 2014 Record-Hot Spring in Korea ................................................ 95

20. Human Contribution to the 2014 Record High Sea Surface Temperatures Over the Western Tropical And Northeast Pacific Ocean.

21. The 2014 Hot, Dry Summer in Northeast Asia .............................................................................. 105

22. Role of Anthropogenic Forcing in 2014 Hot Spring in Northern China........................................... III

23. Investigating the Influence of Anthropogenic Forcing and Natural Variability on the 2014 Hawaiian Hurricane Season.

24. Anomalous Tropical Cyclone Activity in the Western North Pacific in August 2014 .................. 120

25. The 2014 Record Dry Spell at Singapore: An Intertropical Convergence Zone (ITCZ) Drought.

26. Trends in High-Daily Precipitation Events in Jakarta and the Flooding of January 2014 ................13।

27. Extreme Rainfall in Early July 2014 in Northland, New Zealand-Was There an Anthropogenic Influence?

28. Increased Likelihood of Brisbane, Australia, G20 Heat Event Due to Anthropogenic Climate Change.

29. The Contribution of Anthropogenic Forcing to the Adelaide and Melbourne, Australia, Heat Waves of January 2014

30 Contributors to the Record High Temperatures Across Australia in Late Spring 2014 ............... 149

3I. Increased Risk of the 2014 Australian May Heatwave Due to Anthropogenic Activity... 154

32. Attribution of Exceptional Mean Sea Level Pressure Anomalies South of Australia in August 2014

33. The 2014 High Record of Antarctic Sea Ice Extent........................................................................ 163

34. Summary and Broader Context........................................................................................................... 168 


\section{ABSTRACT_Stephanie C. Herring, Martin P. Hoerling, James P. Kossin, Thomas C. Peterson, and Peter A. Stott}

Understanding how long-term global change affects the intensity and likelihood of extreme weather events is a frontier science challenge. This fourth edition of explaining extreme events of the previous year (2014) from a climate perspective is the most extensive yet with 33 different research groups exploring the causes of 29 different events that occurred in 2014. A number of this year's studies indicate that human-caused climate change greatly increased the likelihood and intensity for extreme heat waves in 2014 over various regions. For other types of extreme events, such as droughts, heavy rains, and winter storms, a climate change influence was found in some instances and not in others. This year's report also included many different types of extreme events. The tropical cyclones that impacted Hawaii were made more likely due to human-caused climate change. Climate change also decreased the Antarctic sea ice extent in 2014 and increased the strength and likelihood of high sea surface temperatures in both the Atlantic and Pacific Oceans. For western U.S. wildfires, no link to the individual events in 2014 could be detected, but the overall probability of western U.S. wildfires has increased due to human impacts on the climate.
Challenges that attribution assessments face include the often limited observational record and inability of models to reproduce some extreme events well. In general, when attribution assessments fail to find anthropogenic signals this alone does not prove anthropogenic climate change did not influence the event. The failure to find a human fingerprint could be due to insufficient data or poor models and not the absence of anthropogenic effects.

This year researchers also considered other humancaused drivers of extreme events beyond the usual radiative drivers. For example, flooding in the Canadian prairies was found to be more likely because of human land-use changes that affect drainage mechanisms. Similarly, the Jakarta floods may have been compounded by land-use change via urban development and associated land subsidence. These types of mechanical factors reemphasize the various pathways beyond climate change by which human activity can increase regional risk of extreme events. 


\title{
33. THE 2014 HIGH RECORD OF ANTARCTIC SEA ICE EXTENT
}

\author{
F. Massonnet, V. Guemas, N. S. Fučkar, and F. J. Doblas-Reyes
}

The record maximum of Antarctic sea ice resulted chiefly from anomalous winds that transported cold air masses away from the Antarctic continent, enhancing thermodynamic sea ice production far offshore.

Introduction. Antarctic sea ice extent exceeded the symbolic level of 20 million $\mathrm{km}^{2}$ for the first time since 1978, when reliable satellite measurements became available. After the successive records of 2012 and 2013, sea ice extent in 2014 once again reinforced the positive trend observed since the late 1970s. Previous studies have interpreted this trend as the result of powerful atmosphere- and ocean-sea ice feedbacks (Zhang 2007; Goosse and Zunz 2014), freshwater forcing from continental ice-sheet melting (Bintanja et al. 2013), or changes in wind regimes (Holland and Kwok 2012), although this trend was found to be compatible with internal variability (Polvani and Smith 2013). We conduct here a dedicated study to elucidate the origins of a major, and perhaps the most intriguing, climatic event of 2014.

Winter 2014 Antarctic conditions in context. The average September 2014 Antarctic sea ice extent reached 20.10 million $\mathrm{km}^{2}$ according to the National Snow and Ice Data Center Sea Ice Index (Fetterer et al. 2015). This value represented a significant upward departure from the observed positive trend in total sea ice extent (Fig. 33.1a). The 2014 sea ice extent anomaly was the result of a circumpolar increase in sea ice concentration near the ice edge, except in the

\footnotetext{
AFFILIATIONS: MASSONNET-Georges Lemaître Centre for Earth and Climate Research, Earth and Life Institute, Université catholique de Louvain, Louvain-la-Neuve, Belgium, and Climate Forecasting Unit, Catalan Institute of Climate Sciences, Barcelona, Spain; GuemAs - Climate Forecasting Unit, Catalan Institute of Climate Sciences, Barcelona, Spain, and Centre National de Recherches Météorologiques, Toulouse, France; FučKAR-Climate Forecasting Unit, Catalan Institute of Climate Sciences, Barcelona, Spain; DOBLAS-REYES-Climate Forecasting Unit, Catalan Institute of Climate Sciences, and Catalan Institution for Research and Advanced Studies, and Barcelona Supercomputing Center-Centro Nacional de Supercomputación, Barcelona, Spain
}

DOI:10.1175/BAMS-D-15-00093.I

A supplement to this article is available online $(10.1175$ /BAMS-D-15-00093.2)
Amundsen-Bellingshausen Seas (Fig. 33.1b). The spatial patterns of 2014 anomalies thus matched well the spatial trends in observed sea ice concentration over the past decades (Parkinson and Cavalieri 2012).

Wind is a primary driver of autumn and winter Antarctic sea ice variability at decadal time scales (Holland and Kwok 2012; Holland et al. 2014) through enhanced transport and divergence of sea ice (dynamic contribution), or near-surface air temperature advection, i.e., transport of near-surface air across a temperature gradient (thermodynamic contribution). In 2014, positive sea ice concentration anomalies in September were associated with anomalous southerly winds in the preceding austral winter in the Indian and Ross Sea sectors (Fig. 33.1b). Meanwhile, anomalous northerly winds blew in the Amundsen-Bellingshausen Seas where ice concentration anomalies were negative. Elsewhere around the hemisphere, the link between sea ice anomalies and the meridional component of the wind was less obvious.

While the link between 2014 winds and sea ice concentration seems solid in several regions of the Southern Ocean, three questions remain: 1) Is this link causal? 2) Are sea ice anomalies the result of anomalous dynamic or thermodynamic forcing? 3) Have other factors contributed to the record, namely preconditioning from the ocean in summer, anomalies in precipitation, or freshwater discharge from the Antarctic ice-shelves? To answer these questions, we implement a sensitivity analysis with a state-of-theart ocean-sea ice general circulation model.

Attribution of the 2014 maximum through model experiments. We perform 10 (2005-14) 8-monthlong simulations, labeled "CTRL" in Fig. 33.2, with the Louvain-la-Neuve sea ice model (LIM3; Vancoppenolle et al. 2009) embedded in the Nucleus for European Modelling of the Ocean (NEMO3.3; Madec 2008) ocean model forced by the ERA-Interim atmospheric reanalyses (Dee et al. 2011) following 


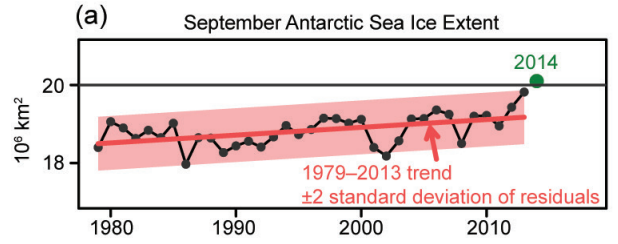

(b) September 2014 Sea Ice Concentration Anomalies $4 \mathrm{~m} \mathrm{~s}^{-1} \rightarrow$ (JAS 2014 wind anomaly)

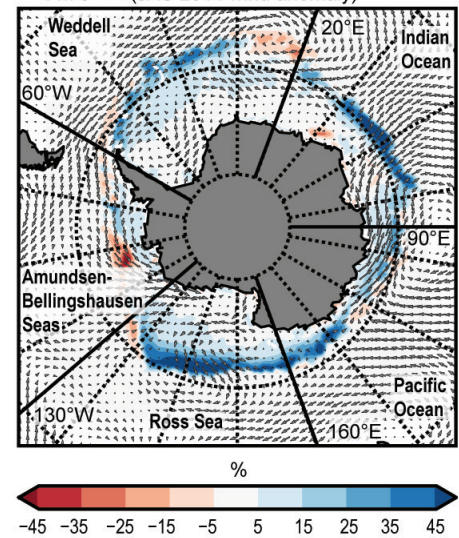

(c)

(c) JAS 2014 Temperature Advection Anomalies $4 \mathrm{~m} \mathrm{~s}^{-1} \rightarrow$ (JAS 2014 wind anomaly)

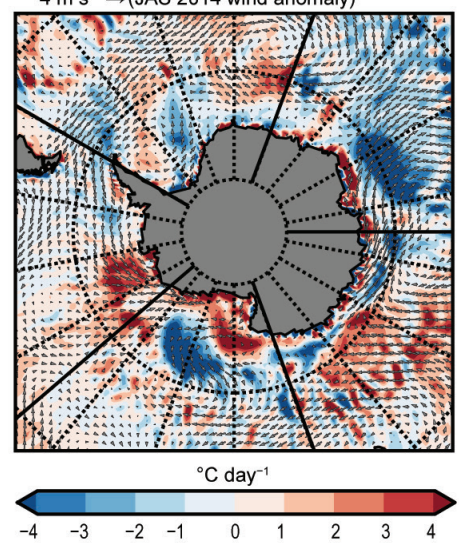

FIG. 33.I. Winter 2014 Antarctic conditions in context. (a) Sep Antarctic sea ice extent as retrieved from satellite imagery (Fetterer et al. 20I5). Sea ice extent is defined throughout the text as the cumulative area of oceanic grid cells containing at least $15 \%$ of ice. The trend line (leastsquares regression) across the period is shown as the red line, and the red shadow is the interval corresponding to two standard deviations of the residuals of the fit. (b) Anomalies of Sep 2014 sea ice concentration relative to 1979-2013 (Eastwood 2014) overlaid by 2014 austral winter [Jul-Aug-Sep (JAS) mean] wind anomalies from the ERA-Interim reanalysis (Dee et al. 20II) relative to the 1979-20I3 average. (c) Anomaly of winter 2014 advection of near-surface temperatures relative to 1979-2013. Advection for $1979-2013$ and 2014 is estimated as $\vec{u} \cdot \nabla T$, i.e., the scalar product between the 10-m JAS ERA-Interim winds and the 2-m JAS mean temperature gradient. The gradient operator is itself estimated using a 6-point centered difference scheme along the meridional and zonal directions, respectively.

the bulk formulae of Large and Yeager (2004). The simulations are initialized on 1 March of each year from the Nucleus for European Modelling of the Ocean Variational data assimilation systemOcean Reanalysis System 4 (NEMOVAR-ORAS4) oceanic reanalysis (Balmaseda et al. 2013) and from a sea ice reconstruction described in the online supplemental material. To account for uncertainty in the atmospheric forcing and initial conditions (ICs), we run ensembles of five members for each year (see online supplemental material). Since the skill of CTRL simulations depends in part on the realism of the atmospheric forcing, it is desirable to know that the ocean-sea ice model responds in a reasonable way to the forcing used in this study. This aspect is also discussed in the online supplemental material.

The CTRL experiment performs well in all sectors of the Southern Ocean except the Pacific Ocean sector
(Fig. 33.2), for reasons that are still to be investigated. Therefore, we exclude this sector from subsequent analyses. Spurious sea ice variability over 2007-10 in the Pacific Ocean sector contaminates the skill of simulated total Antarctic sea ice extent and partly explains why September 2014 is not a maximum in the model. Figure 33.2 also illustrates why the correlation of total Antarctic sea ice extent can be a misleading metric of performance. Maps of gridpoint correlations over the period of interest reveal that more than $50 \%$ of the observed variance in sea ice concentration near the ice edge is explained by the model (Supplemental Fig. S33.2). We therefore argue that the model is adequate to conduct our attribution study given the spatial patterns of sea ice concentration anomalies in September 2014 (Fig. 33.1b). In addition to the CTRL experiment, we run four sensitivity experiments initialized on 1 March 2014. Each sensitivity experiment differs from CTRL by one aspect only. This approach, already implemented in an attribution study of the 2012 Arctic sea ice minimum (Guemas et al. 2013), has the advantage of systematically isolating the role of individual factors that could have explained the 2014 record.

We run a first sensitivity experiment called "WND LOW," in which we substitute surface winds of 2014 for those from earlier years corresponding to the lowest total Antarctic sea ice extents in the model (2007, 2008, 2011, 2012, and 2013, referred to as "low" years hereafter). All other parameters (ICs, near-surface air temperatures, precipitation) are left to their default values for 2014. As shown in Fig. 33.2, the replacement of winds has no significant effect on sea ice extent (that is, the new interval includes the CTRL value) except in the Pacific Sector, which we discard due to suspicious model performance. Because winds in the model only impact the sea ice mass budget through transport and divergence, we exclude the possibil- 
ity that they have contributed dynamically to the 2014 record high.

This, however, does not exclude an indirect thermodynamic contribution of winds to the record by anomalous atmospheric heat advection. To explain the observed close association between winds and sea ice concentration in winter 2014 (Fig. 33.1b), we diagnose the rate of observed near-surface temperature change by advection. This diagnostic suggests that, in 2014, winds have played a role in bringing relatively cold air masses in the Indian Ocean and Ross Sea sectors far offshore, where ice eventually grew more than usual (Fig. 33.1c).

To confirm this hypothesis, we run a second sensitivity experiment, labeled "T2M LOW" in Fig. 33.2, in which we substitute only near-surface air temperatures of 2014 for those from "low" years. This single change in air temperatures results in a significant decrease of 0.41 million $\mathrm{km}^{2}$ in total sea ice extent. More than the half of this decrease is due to a significant response of simulated sea ice in the Indian Ocean sector (where ice concentration reached anomalously high levels, Fig. 33.1b). Whether the same process was at play in the Ross Sea sector is less clear, given the lack of model response to surface temperature change in this sector. We conclude that the 2014 anomalous near-surface thermal conditions, resulting themselves from anomalous winds, favored the record high in 2014, since sea ice extent could have been lower than 2012 and 2013 otherwise.

We are aware that the experimental setup proposed has limitations. The atmospheric state forcing the model is no longer in dynamical balance when either temperatures or winds are replaced. We find, however, the two effects to be additive: a simulation
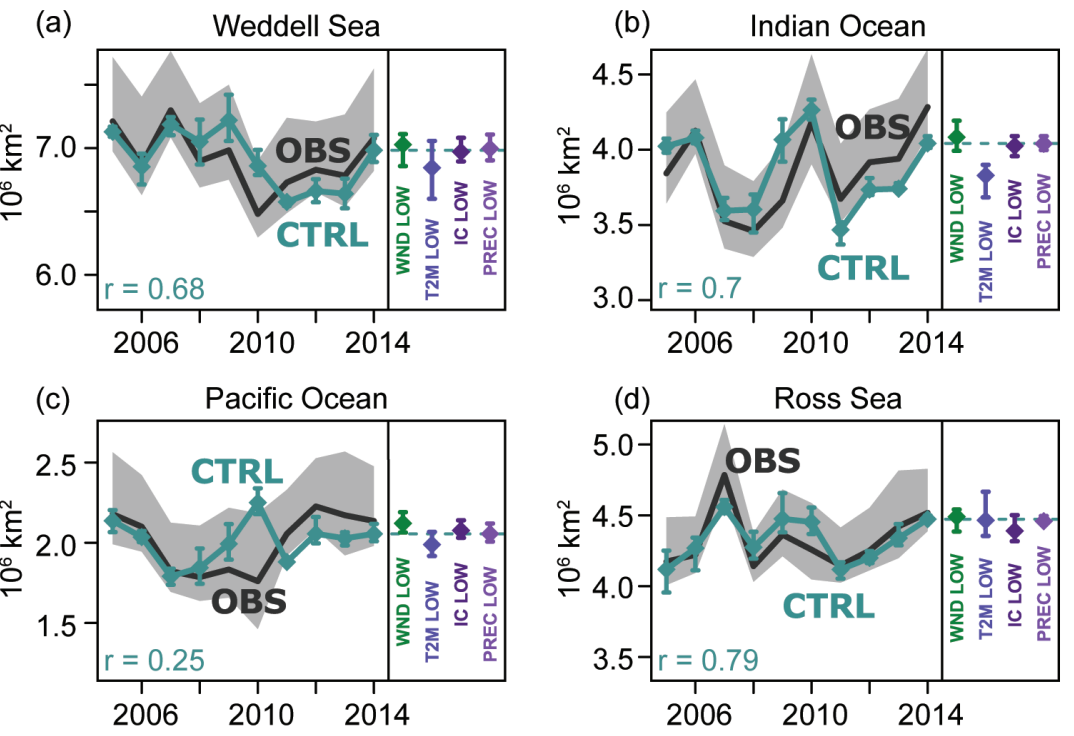

(e) Amundsen-Bellingshausen Seas
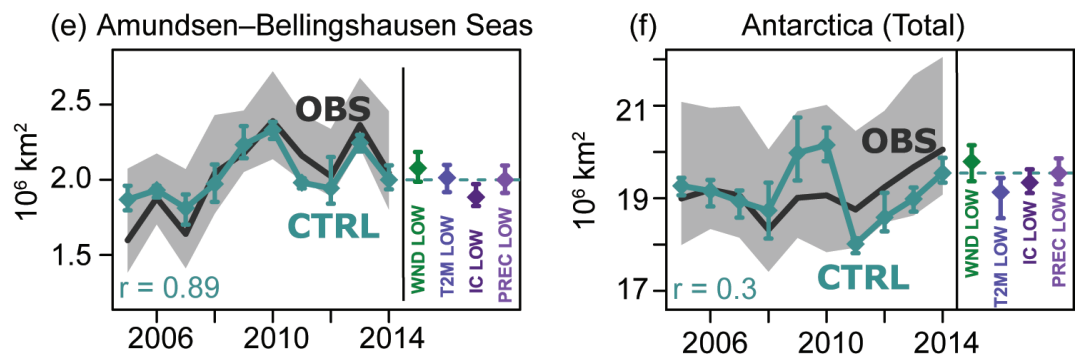

FIG. 33.2. Model sensitivity analyses. Sea ice extent as observed (black line; Eastwood 2014) and simulated (colors) by the NEMO-LIM3 ocean-sea ice model in various sectors of the Southern Ocean, corresponding to those identified in Fig. 33. Ib. The CTRL simulation runs from 2005 to 2014 with initial conditions and atmospheric forcings from these years. The CTRL time series have been recentered on the time-mean of observed time series to account for systematic biases due to differences in land-sea masks. The correlations between the CTRL and observed time series are reported in the lower left corner of each panel. Gray shading corresponds to the estimated uncertainty in sea ice extent, based on a $14 \%$ nominal error in sea ice concentration typical of winter conditions (see the reprocessed products of Eastwood et al. 2014). In the right part of each panel, box plots refer to the four sensitivity experiments for 2014 described in the text: disabling the 2014 winds (WND LOW), near-surface air temperatures (T2M LOW), initial conditions (IC LOW), and precipitation (PREC LOW). The horizontal dashed line is the $\mathbf{2 0 1 4}$ level for comparison. All error bars represent the range (minimum to maximum value) of the five-member ensembles, and diamonds represent the mean.

where both wind and temperatures were replaced would give a total sea ice extent response consistent with the cumulated responses of the individual simulations (not shown here).

In a third experiment ("IC LOW"), we substitute the 1 March 2014 oceanic and sea ice ICs with those from "low" years. No significant reduction is found except in the Amundsen-Bellingshausen Seas sector. In this sector, modeled sea surface temperatures were in fact colder by up to $1.5^{\circ} \mathrm{C}$ than for "low" years in 
March 2014. We conclude that oceanic preconditioning did not play a fundamental role in explaining the sea ice record of September 2014.

We finally test whether anomalous hydrological conditions could have explained the 2014 anomaly. We first investigate the role of the atmospheric hydrological cycle: we replace the 2014 solid and liquid precipitations by those of "low" years. Increased precipitation could reduce upper-ocean density and convective overturning, thereby decreasing sea ice melt (Zhang 2007). However, we find no evidence that this factor has played a significant role in driving sea ice extent to a record in 2014 (Fig. 33.2). Regarding the role of the continental hydrological cycle, we have to acknowledge that the model is forced with climatological runoff data. That is, proper ocean-ice-sheet interactions are absent, making a clean sensitivity experiment impossible. Applying a 0.1 PSU decrease in the 1 March 2014 ocean salinity IC in the top 50 $\mathrm{m}$ and south of $55^{\circ} \mathrm{S}$ increased the total Antarctic sea ice extent of September 2014 by 0.20 million $\mathrm{km}^{2}$ (not shown here). However, we cannot conclude that this mechanism was responsible for the 2014 record since, to our knowledge, no robust estimates of the freshening distribution of the upper-ocean due to Antarctic melt are available for 2014.

\section{Conclusion: What drove the 2014 record of Antarctic sea} ice extent? Following the results of both observational (Fig. 33.1) and model sensitivity (Fig. 33.2) analyses, we find that the primary cause for the 2014 record is anomalous thermodynamic sea ice growth near the ice edge in the Indian Ocean due to anomalous southerly advection of cold air there (Fig. 33.1c). Anomalous winds over winter 2014 are themselves the consequence of a strong dipole of mean sea level pressure anomaly at the boundaries of this sector (Supplemental Fig. S33.3). Oceanic preconditioning appears to have a secondary, but not negligible, influence on the total 2014 sea ice anomaly.

The 2014 Antarctic sea ice extent record can be explained as the superposition of a long-term, positive trend with a large positive anomaly for that particular year (Fig. 33.1a). Unlike the Arctic where the imprint of anthropogenic climate change can be detected in the multidecadal sea ice loss (Min et al.2008), a rigorous attribution statement is not as straightforward for the long-term observed increase in Antarctic sea ice extent. Recent studies using coupled models of different complexity and at various resolutions (Sigmond and Fyfe 2012, 2014; Bitz and Polvani 2012; Ferreira et al. 2014) found evidence of a negative response of total Antarctic sea ice extent to stratospheric ozone depletion at multidecadal time scales. Shorter timescale variability of sea ice extent and concentration has been linked to large-scale atmospheric variability, such as the Southern Annular Mode (SAM; Lefebvre et al. 2004; Stammerjohn et al. 2008; Simpkins et al. 2012). However, in 2014, the winter (JAS) index of the SAM did not display a particular polarity (not shown here). Furthermore, anomalies in mean sea level pressure for winter 2014 (Supplemental Fig. S33.3) did not display a SAM-like signature. In light of our results and those from earlier studies, it is therefore difficult to formulate a robust attribution statement for explaining the 2014 record of Antarctic sea ice extent.

ACKNOWLEDGMENTS. We wish to thank Editor-in-Chief J. Rosenfeld, Editor T. Peterson and two anonymous reviewers for handling and commenting on our manuscript. François Massonnet is a F.R.S. FNRS Post-Doctoral Researcher. The research leading to these results has also received funding from the EU Seventh Framework Programme FP7 (2007-2013) under grant agreements 308378 (SPECS) and 607085 (EUCLEIA) and CGL2012-31987 (PICA-ICE).

\section{REFERENCES}

Balmaseda, M. A., K. Mogensen, and A. T. Weaver, 2013: Evaluation of the ECMWF ocean reanalysis system ORAS4. Quart. J. Roy. Meteor. Soc., 139, 1132-1161, doi:10.1002/qj.2063.

Bintanja, R., G. J. van Oldenborgh, S. S. Drijfhout, B. Wouters, and C. A. Katsman, 2013: Important role for ocean warming and increased ice-shelf melt in Antarctic sea-ice expansion. Nat. Geosci., 6, 376379, doi:10.1038/ngeo1767.

Bitz, C. M., and L. M. Polvani, 2012: Antarctic climate response to stratospheric ozone depletion in a fine resolution ocean climate model. Geophys. Res. Lett., 32, L20705, doi:10.1029/2012GL053393.

Dee, D. P., and Coauthors, 2011: The ERA-interim reanalysis: Configuration and performance of the data assimilation system. Quart. J. Roy. Meteor. Soc., 137, 553-597, doi:10.1002/qj.828.

Eastwood, S., Ed., 2014: Sea ice product user's manual. Ocean and Sea Ice Satellite Application Facilities, 38 pp. [Available online at http://osisaf.met.no/docs losisaf_ss2_pum_ice-conc-edge-type.pdf.] 
Ferreira, D., J. Marshall, C. M. Bitz, S. Solomon, and A. Plumb, 2015: Antarctic Ocean and sea ice response to ozone depletion: A two-time-scale problem. J. Climate, 28, 1206-1226, doi:10.1175/JCLI-D -14-00313.1.

Fetterer, F., K. Knowles, W. Meier, and M. Savoie, 2015: Sea ice index. National Snow and Ice Data Center, Boulder, CO, digital media. [Available online at http://nsidc.org/data/docs/noaa/g02135_seaice _index/.]

Goosse, H., and V. Zunz, 2014: Decadal trends in the Antarctic sea ice extent ultimately controlled by iceocean feedback. Cryosphere, 8, 453-470, doi:10.5194 /tc-8-453-2014.

Guemas, V., F. J. Doblas-Reyes, A. Germe, M. Chevallier, and D. Salas y Mélia, 2013: September 2012 Arctic sea ice minimum: Discriminating between sea ice memory, the August 2012 extreme storm, and prevailing warm conditions [in "Explaining Extreme Events of 2012 from a Climate Perspective"]. Bull. Amer. Meteor. Soc., 94 (9), S20-S22.

Holland, P. R., and R. Kwok, 2012: Wind-driven trends in Antarctic sea-ice drift. Nat. Geosci., 5, 872-875, doi:10.1038/ngeo1627.

—, N. Bruneau, C. Enright, M. Losch, N. T. Kurtz, and R. Kwok, 2014: Modeled trends in Antarctic sea ice thickness. J. Climate, 27, 3784-3801, doi:10.1175 /JCLI-D-13-00301.1.

Large, W. G., and S. G. Yeager, 2004: Diurnal to decadal global forcing for ocean and sea-ice models: The data sets and flux climatologies. NCAR Tech. Note NCAR/TN-460+STR, 105 pp., doi:10.5065/D6KK98Q6.

Lefebvre, W., H. Goosse, R. Timmermann, and T. Fichefet, 2004: Influence of the Southern Annular Mode on the sea ice-ocean system. J. Geophys. Res., 109, C09005, doi:10.1029/2004JC002403.

Madec, G., 2008: NEMO ocean engine. Note du Pôle de modélisation de l'Institut Pierre-Simon Laplace 27, 357 pp. [Available online at www.nemo-ocean.eu /About-NEMO/Reference-manuals.]

Min, S.-K., X. Zhang, F. W. Zwiers, and T. Agnew, 2008: Human influence on Arctic sea ice detectable from early 1990s onwards. Geophys. Res. Lett., 35, L21701, doi:10.1029/2008GL035725.

Parkinson, C. L., and D. J. Cavalieri, 2012: Antarctic sea ice variability and trends, 1979-2010. Cryosphere, 6, 871-880, doi:10.5194/tc-6-871-2012.

Polvani, L. M., and K. L. Smith, 2013: Can natural variability explain observed Antarctic sea ice trends? New modeling evidence from CMIP5. Geophys. Res. Lett., 40, 3195-3199, doi:10.1002/grl.50578.
Sigmond, M., and J. Fyfe, 2010: Has the ozone hole contributed to increased Antarctic sea ice extent? Geophys. Res. Lett., 37, L18502, doi:10.1029/2010GL044301.

— , and ——, 2014: The Antarctic sea ice response to the ozone hole in climate models. J. Climate, 27, 1336-1342, doi:10.1175/JCLI-D-13-00590.1.

Simpkins, G. R., L. M. Ciasto, D. W. J. Thompson, and M. H. England, 2012: Seasonal relationships between large-scale climate variability and Antarctic sea ice concentration. J. Climate, 25, 5451-5469, doi:10.1175/JCLI-D-11-00367.1.

Stammerjohn, S., D. G. Martinson, R. C. Smith, X. Yuan, and D. Rind, 2008: Trends in Antarctic annual sea ice retreat and advance and their relation to El Niño-Southern Oscillation and Southern Annular Mode variability. J. Geophys. Res., 113, C03S90, doi:10.1029/2007JC004269.

Vancoppenolle, M., T. Fichefet, H. Goosse, S. Bouillon, G. Madec, and M. A. Morales Maqueda, 2009: Simulating the mass balance and salinity of Arctic and Antarctic sea ice. 1. Model description and validation. Ocean Modell., 27, 33-53.

Zhang, J., 2007: Increasing Antarctic sea ice under warming atmospheric and oceanic conditions. $J$. Climate, 20, 2515-2529. 


\begin{tabular}{|c|c|c|c|}
\hline \multicolumn{4}{|c|}{ ON EVENT STRENGTH † } \\
\hline & INCREASE & DECREASE & NOT FOUND OR UNCERTAIN \\
\hline Heat & $\begin{array}{l}\text { Australia (Ch. 31) } \\
\text { Europe (Ch.13) } \\
\text { S. Korea (Ch. 19) }\end{array}$ & & $\begin{array}{l}\text { Australia, Adelaide \& Melbourne } \\
\text { (Ch. 29) } \\
\text { Australia, Brisbane (Ch.28) }\end{array}$ \\
\hline Cold & & Upper Midwest (Ch.3) & \\
\hline $\begin{array}{l}\text { Winter } \\
\text { Storms and } \\
\text { Snow }\end{array}$ & & & $\begin{array}{l}\text { Eastern U.S. (Ch. 4) } \\
\text { N. America (Ch. 6) } \\
\text { N. Atlantic (Ch. 7) }\end{array}$ \\
\hline $\begin{array}{c}\text { Heavy } \\
\text { Precipitation }\end{array}$ & Canada** (Ch. 5) & & $\begin{array}{l}\text { Jakarta***** (Ch. 26) } \\
\text { United Kingdom } * * * *(C h .10) \\
\text { New Zealand (Ch. 27) }\end{array}$ \\
\hline Drought & $\begin{array}{l}\text { E. Africa (Ch. 16) } \\
\text { E. Africa* (Ch. 17) } \\
\text { S. Levant (Ch. 14) }\end{array}$ & & $\begin{array}{l}\text { Middle East and S.W. Asia } \\
(\text { Ch. 15) } \\
\text { N.E. Asia (Ch. 2I) } \\
\text { Singapore (Ch. 25) }\end{array}$ \\
\hline $\begin{array}{l}\text { Tropical } \\
\text { Cyclones }\end{array}$ & & & $\begin{array}{l}\text { Gonzalo (Ch. II) } \\
\text { W. Pacific (Ch. 24) }\end{array}$ \\
\hline Wildfires & & & California (Ch. 2) \\
\hline $\begin{array}{l}\text { Sea Surface } \\
\text { Temperature }\end{array}$ & $\begin{array}{l}\text { W. Tropical \& N.E. Pacific (Ch. 20) } \\
\text { N.W. Atlantic \& N.E. Pacific (Ch. 13) }\end{array}$ & & \\
\hline $\begin{array}{l}\text { Sea Level } \\
\text { Pressure }\end{array}$ & S. Australia (Ch. 32) & & \\
\hline $\begin{array}{l}\text { Sea Ice } \\
\text { Extent }\end{array}$ & & & Antarctica (Ch. 33) \\
\hline
\end{tabular}

† Papers that did not investigate strength are not listed.

t† Papers that did not investigate likelihood are not listed.

* No influence on the likelihood of low rainfall, but human influences did result in higher temperatures and increased net incoming radiation at the surface over the region most affected by the drought.

** An increase in spring rainfall as well as extensive artificial pond drainage increased the risk of more frequent severe floods from the enhanced rainfall.

*** Evidence for human influence was found for greater risk of UK extreme rainfall during winter 2013/14 with time scales of 10 days

***** The study of Jakarta rainfall event of 2014 found a statistically significant increase in the probability of such rains over the last 115 years, though the study did not establish a cause. 


\section{ON EVENT LIKELIHOOD ††}

Argentina (Ch. 9)

Australia (Ch. 30, Ch. 31)

Australia, Adelaide (Ch. 29)

Australia, Brisbane (Ch. 28)

Melbourne, Australia (Ch. 29)

Europe (Ch. 13)

S. Korea (Ch. 19)

China (Ch. 22)

Cold
Winter
Storms and
Snow

Heavy
Precipitation

(a)

N. America (Ch. 6)

S. France (Ch. 12)

Middle East and S.W. Asia (Ch. 15)

Drought

E. Africa (Ch. 16)

S. Levant (Ch. 14)

E. Africa* (Ch. 17)

N.E. Asia (Ch. 2I)

Wildfires

California (Ch. 2)

\section{W. Tropical \& N.E. Pacific}

Sea Surface

Temperature

(Ch. 20)

N.W. Atlantic \& N.E. Pacific (Ch. 13)

Sea Level

Pressure

S. Australia (Ch. 32)

Sea Ice

Extent

.

Antarctica (Ch. 33)

† Papers that did not investigate strength are not listed.

t† Papers that did not investigate likelihood are not listed.

* No influence on the likelihood of low rainfall, but human influences did result in higher temperatures and increased net incoming radiation at the surface over the region most affected by the drought.

** An increase in spring rainfall as well as extensive artificial pond drainage increased the risk of more frequent severe floods from the enhanced rainfall.

*** Evidence for human influence was found for greater risk of UK extreme rainfall during winter 2013/14 with time scales of 10 days

**** The study of Jakarta rainfall event of 2014 found a statistically significant increase in the probability of such rains over the last II5 years, though the study did not establish a cause. 